\title{
On the cost of shame
}

\section{Comment on "Nudging by shaming, shaming by nudging"}

\section{Emma Tieffenbach ${ }^{\star}$}

\section{Abstract}

In his editorial, Nir Eyal argues that a nudge can exploit our propensity to feel shame in order to steer us toward certain choices. We object that shame is a cost and therefore cannot figure in the apparatus of a nudge.

Keywords: Nudge, Health, Cost, Shame, Shaming

Copyright: (c) 2014 by Kerman University of Medical Sciences

Citation: Tieffenbach E. On the cost of shame: Comment on "Nudging by shaming, shaming by nudging". Int $J$

Health Policy Manag 2014; 3: 409-411. doi: 10.15171/ijhpm.2014.125

\section{Article History:}

Received: 15 September 2014 Accepted: 17 November 2014 ePublished: 18 November 2014

\section{${ }^{*}$ Correspondence to:}

Emma Tieffenbach

Email: emma.tieffenbach@unige.ch

\section{Introduction}

In his thought-provoking editorial (1), Nir Eyal shows that a nudge may be related to our propensity to feel shame in two different ways. A nudge may, firstly, promote certain choices by making others shameful. The fear of shame could, as Eyal illustrates, deter people from smoking in the area dedicated to their habit, from neglecting to take their pills in the presence of treatment observers, from going for a soda refill or from requesting to be treated by a senior staff member at the hospital. Having people choose option $a$ can thus be achieved by associating option $b$ with an experience of shamee. A nudge may, secondly, elicit guilt as a perverse effect. This is because the choice it promotes is the sort for which one remains fully responsible. This is arguably an appealing aspect of being nudged when things go well (do not we like to choose?). Not so in the contrary case, however. No mild consolation partly compensating for the fatality of a surgery will be available on consideration that one did not have any choice. Guilt will ensue.

Eyal takes the second relation to be "more critical" than the first one. However, history abounds of unappealing shaming practices, that is, of deliberate elicitations of shame (2-4), in light of which the first connection looks as troublesome. Moreover, because these practices are usually viewed as penalties, their accommodation within the soft realm of nudges can be questioned. In order to be compatible with nudges, the use of shaming would have to meet a few constraints. It will have, in particular, to promote options without neither banning others nor significantly changing agents' incentives. Whether shaming meets the second assumption is questionable and is the focus on the present commentary. I show that shame is a cost in the relevant sense and thus cannot figure in the apparatus of nudges. I shall however make a few remarks about the first requirement, namely, the absence of a ban, as some of the cases considered by Eyal seem to contradict it.

\section{Shaming and banning}

Banning smoking in the workplace, or within thirty feet of an entrance, is what it is: a ban on smoking. And so is the ban on the sale of large cups of sugary soda. These examples thus seem to misfit the category of nudges, which, by definition, do not forbid any options.

Even if they involve some restriction, it remains possible, however, to view these two cases as eligible instances of nudges. This is because the ban constraints, rather than prohibits, certain behaviours. Indeed, the smoker is not forbidden to smoke but to smoke at a certain place. Smoking is thus an option that remains available to him, only at the price of a few more steps. Likewise, New Yorkers are not forbidden to drink and, in fact, they can drink the amount of soda they want. They will just have to refill their cups more often than they would have in the absence of a ban on certain size of cups. In both cases, the ban does impact on the behaviour of people but without blocking any options. It should therefore be compatible with a nudge.

\section{The cost of shame}

To serve in nudging, an experience of shame would have to be (nearly) costless and this does not seem to be the case. Shame is indeed a cost in two relevant senses. First, it is utterly unpleasant. No one will find the experience of shame, guilt or embarrassment desirable. Shame is certainly the most unbearable of these so-called social emotions (5-7), judging among others by the number of suicides it causes. To be embarrassed is to be only mildly unhappy even if it is to be very much aroused, that is, to undergo intense and durable physiological changes. The latter have, in turn, many costly effects on attention span (8). The difference may be that, unlike shame and guilt, embarrassment is caused by mere exposure to others, without any evaluation of oneself being involved $(9,10)$. It is embarrassing to stain one's skirt, but what ideal or principle did I violate when I let the tomato sauce drop onto it? All instances of social emotions are, to some extent, painful both in terms of negative valence and arousal. It therefore makes sense to construe them, as some economists do, as physic costs $(11,12)$.

Another reason to consider shame as a cost is the possibility 
to subject it to a cost-benefit analysis $[(11,12)$, see also (7) for a critical view on this approach]. The smoker weights the emotional dissatisfaction of embarrassment against the satisfaction of smoking. The patient balances the benefits of not taking her pills with the cost of having to face the treatment observer's witnessing him. The cost-benefit model of emotion nicely accounts for these trade-offs between the fear of shame and self-interested considerations. It presents the advantage of accounting for the fact that many smokers do not go on with their habit at all cost but only when the pleasure of smoking is sufficiently high to trump the discomfort of being the focus of other's gaze.

If a shameful choice is, as we argue, a costly experience, the difference between an experience of shame and a fine ceases to be obvious. There are however various ways of resisting this conclusion, which will next be critically reviewed.

\section{Mild shame}

One may first argue that, if a small increase of cost really is acceptable as a nudge, as their proponents say (13), the cost of shame will only have to be low enough for figuring among the mechanisms of nudges. A choice architect who considers using shame as a nudge will make sure its discomfort is sufficiently mild to keep the incentives unchanged. For this, he may organize the context so that a subtle embarrassment is more likely to be elicited than more a acutely painful guilt or a shame, which are too distressing to be employed as a nudge.

One may however object that it is too optimistic to assume that emotions can be elicited in others with that degree of precision. While we may predict that patients will be steered away from neglecting to take their treatments by having them exposed to an audience, less easy to control, it seems, will be the specific nature of the emotions that will be elicited in this manner, and let alone its intensity, both of which will depend on various unpredictable idiosyncratic factors. An innocuous embarrassment may unpredictably misfire into a much more painful and costly humiliation, or, alternatively, into anger (14) in a way that is not systematically predictable, even less so controllable.

\section{Unconscious shame}

Another way of avoiding to recognize to cost of shame and thus its eligibility as a nudge would be to distinguish between two ways it could support certain options. One is when it is consciously anticipated as a painful, costly experience. Shame, in this case, consciously operates on our mind in a way that is not different from a fine. Alternatively, it may be suggested, shame may unconsciously prompts certain choice but not via reflection. In this latter case, shame influences our behaviour without being an element of conscious deliberation. The latter kind of shame, it may be argued in response to our objection, is a nudge while the former is not. The idea that emotions can unconsciously weigh on our decision-making is however controversial (16). What could it possibly mean to say that the soda drinker's fear of embarrassment unconsciously drives her to renounce to another refill? One possibility would be that, unlike the fear she feels when she watches a horror movie, her fear of embarrassment triggers no physiological change (17). Another possibility would be that she is conceptually confused so that she mistakes the guilt she actually fears for a case of embarrassment. Either way, shame has a negative valence and is thus correctly construed as a cost.

\section{Felt as dread but objectively a trifle}

Still another way to get around the problem of the cost of social emotions is to argue, as Eyal does, that their fear "pressures us more than it should" or, as he also says, that a social stigma is "objectively a trifle but which we dread" (1). Consider the smoker who renounces to his habit for fear of another's gaze. Is not he according too much significance to the opinions of others when in fact they may not even be giving him a second glance? The idea is that we are disproportionally averse to shame. Only someone whose rationality is severely bounded will seriously risk death or even injury just to avoid embarrassment. However unpleasant asking for a well-trained surgeon might be, it is clearly nothing in comparison to the fatalities of a failed surgery. Yet we are prone to reach the opposite conclusion. The fear of shame biases us toward options we have no objective reason to choose (7). This fear, therefore, qualifies as the sort of irrational propensities that a nudge may exploit for the sake of our own good.

The argument, one may reply, makes the uneasy assumption that people mistakenly assess the cost of shame when they fear it. But the notion of cost is too subjective for allowing any error of commission (i.e. ascribing cost to objectively costless option) of this type. It is enough that someone prefers avoiding embarrassment, one may argue, for the latter to raise the cost of smoking in the smoking area.

One may also object that shame can enter into decisionmaking without necessarily affecting the rationality of choice itself. The benefit of avoiding another's withering glance may be greater, after all, than the rather brief delight of a nicotine high. And why should not it be acceptable to find the diminishing marginal pleasure of another glass of soft drink not worth the discomfort, however objectively low the latter might be, of suffering an episode of embarrassment? While it is true that emotions often distort our judgement about what is in our interest to do, all cases discussed by Eyal might not be illustrative of this admittedly well-known subverting power.

Finally, one may say that when shame does hinder our practical judgement, its importance will not, or not only, be overestimated as Eyal suggests. Anticipated shame may as likely be weighted insufficiently rather than too much (7). Someone craving for nicotine after a ten hours flight could easily underestimate how embarrassing displaying her addiction in the glass-widowed smoking area will be.

\section{Conclusion}

By highlighting the deterring role that shame plays in certain nudges, Eyal has not only casted light on their emotional functioning, he also has drawn our attention, even if unintentionally, to their hidden cost. After having looked at various inconclusive ways of making such cost compatible with the soft realm of nudges, we may conclude that a nudge 
may not be as cheap to avoid as it is supposed to be.

\section{Acknowledgements}

The author is grateful to Fabrice Teroni and two anonymous referees for their helpful comments.

\section{Ethical issues}

Not applicable.

\section{Competing interests}

Author declares that she has no competing interests.

Author's contribution

$\mathrm{ET}$ is the single author of the manuscript.

\section{References}

1. Eyal N. Nudging by shaming, shaming by nudging. Int $J$ Health Policy Manag 3: 53-6; 2014. doi: 10.15171/ijhpm.2014.68

2. Nussbaum M. Hiding from Humanity: Disgust, Shame, and the Law. Princeton, NJ/Oxford: Princeton University Press; 2004.

3. Elison J, Harter S. Humiliation: Causes, Correlates and Consequences. In: Tracy JL, Robins RW, and Tangney JP, editors. The Self-Conscious Emotions. New York: The Guilford Press; 2007. p. 310-29.

4. Deonna J, Rodogno R, Teroni F. In Defense of Shame: The Faces of an Emotion. Chapters 7 and 8. Oxford: Oxford University Press; 2012.

5. Williams B. Shame and Necessity. Berkeley: University of
California Press; 1993.

6. Wolheim R. On the Emotions. New Haven, Conn.: Yale University Press; 1999.

7. Elster J. Alchemies of the Mind, Rationality and the Emotions. Cambridge: Cambridge University Press; 1999.

8. Russell JA. A circumplex model of affect. J Pers Soc Psychol 1980; 39: 1161-78.

9. Lewis M. Shame and Stigma. In: Gilbert P, Andrews B, editors. Shame: Interpersonal Behavior, Psychopathology and Culture. New York/Oxford: Oxford University Press; 1988. p. 126-40.

10. Sabini J, Silver M. In Defence of Shame: Shame in the context of Guilt and Embarrassment. Journal for the Theory of Social Behavior 1997; 27: 1-15. doi: 10.1111/1468-5914.00023

11. Becker G. Accounting for Tastes. Cambridge, MA: Harvard University Press; 1996.

12. Robert F. Passions within Reason. New York: Norton; 1988.

13. Sunstein CR, Thaler RH. Nudge: Improving Decisions About Health, Wealth, and Happiness. 1st edition. New Haven, CT: Yale University Press; 2008. doi: 10.1007/s10602-008-9056-2

14. Tangney JP, Wagner PE, Fletcher C, Gramzow R. Shamed into anger? The relation of shame and guilt to anger and selfreported aggression. J Pers Soc Psychol 1992; 62: 669-75.

15. Elster J. Sour Grapes. Cambridge: Cambridge University Press; 1993.

16. Deonna J, Terroni F. The Emotions. A philosophical Introduction. London and New York: Routledge; 2012.

17. Gordon RM. The Structure of Emotions. Cambridge: Cambridge University Press; 1997. 